\title{
Numerical Simulation and Experimental Verification of CMOD in SENT Specimen: Application on FCGR of Welded Tool Steel
}

\author{
Amir SULTAN ${ }^{1 \dagger \dagger}$, Riffat Asim PASHA ${ }^{1)}$, Mifrah ALI ${ }^{1)}$, Muhammad Zubair KHAN ${ }^{1)}$, \\ Muhammad Afzal KHAN ${ }^{2)}$, Naeem Ullah DAR ${ }^{1)}$ and Masood SHAH ${ }^{1)}$ \\ 1) Department of Mechanical Engineering, University of Engineering and Technology, Taxila 47050, Pakistan \\ 2) International Islamic University, Islamabad 44000, Pakistan
}

[Manuscript received 7 August, 2012, in revised form 20 September, 2012]

(C) The Chinese Society for Metals and Springer-Verlag Berlin Heidelberg

\begin{abstract}
Single-edged notched tension (SENT) specimen is used to study the fatigue crack growth rate (FCGR) behavior of AISI 50100 steel using MTS 810. Calibration tests are run to get plots of crack mouth opening displacement (CMOD) vs. load and CMOD vs. crack length-to-width ratio with the known crack lengths. Numerical simulation is also done to try to establish a relation between crack length and CMOD. FCGR of welded and un-welded specimens are plotted against stress intensity factor range to show the effect of welding on fatigue crack growth rate of AISI 50100 steel. The experimentally obtained CMOD values are compared with values obtained by numerical simulation using ABAQUS/Standard ${ }^{\mathrm{TM}}$ software package. Results show that numerical values are in good agreement with experimental data for small crack lengths and lower values of applied load.
\end{abstract}

KEY WORDS: Tool steel; Weld; Single-edged notched tension (SENT); CMOD; Fatigue crack growth rate (FCGR)

\section{Introduction}

Though welding is the most common method (and in some cases the only one) for fabricating metallic parts, at the same time it also poses different challenges when put into service due to the changes in the structure and residual stresses induced as a result of welding. There is a need to develop understanding as how welded components behave particularly under the influence of repeated loading that is to know how fatigue cracks initiate and/or propagate in weldments and this problem is more pertinent in components made of high strength steels ${ }^{[1,2]}$.

Study of fatigue life of weldments may be divided into two broad categories. One is the endurance limit study which has been extensively explored by researchers ${ }^{[3,4]}$ and the other is FCGR inside welded material. Much work has been done on the endurance limits of the welded structures. Different suggestions have also been proposed to increase the endurance limit

† Corresponding author. Assist. Prof.; Tel: +92 3335709933; Email address: amir.sultan@uettaxila.edu.pk (Amir SULTAN)

DOI: $10.1007 / \mathrm{s} 40195-012-0135-\mathrm{z}$ inducing compressive residual stresses near the fatigue critical zone of the weldment to improve its fatigue life $^{[5]}$. Some more methods have been listed below. Most of the suggested proposals pertain to increasing the crack initiation life of the welded structure.

Zhang et al..$^{[6]}$ concluded that burr grinding increased the fatigue endurance of the fillet welds by a factor greater than 4 . Nykanen et al. ${ }^{[7]}$ suggested that geometrical variations of the weld throat size have only a small effect on the fatigue strength if the depth of an initial toe crack is greater than $0.2 \mathrm{~mm}$, thus suggesting that the crack behave in a geometry independent manner once its length is beyond a certain value, thus as the depth of the initial toe crack increases, the local geometrical effects disappear.

In the work on fatigue crack propagation of $\mathrm{D} 6 \mathrm{AC}$ steel plates and laser welds, Tasy et al. ${ }^{[8]}$ found that fatigue crack growth rates (FCGRs) of the weld metal $(\mathrm{WM})$ and the heat affected zone (HAZ) were less than those of base metal (BM) for similar stress intensity factor ranges $\left(\Delta K_{\mathrm{s}}\right)$. They also tested the effects of post weld heat treatment which seems to reduce the dip in the $\mathrm{d} a / \mathrm{d} N$ vs. $\Delta K$ curve in regions of HAZ and WM with a corresponding increase in the post weld heat treatment temperature. Crack propagation 
rate is also found to be dependent on the specimen thickness, i.e., it reduces with reduction in specimen thickness and vice versa ${ }^{[9]}$, which has to be considered while characterizing welds in thick base metals or high strength material sheet.

In earlier work based on $\mathrm{FE}$ analysis, researchers investigated the effect of height $(H)$ to width $(W)$ ratio on SIF ${ }^{[10,11]}$ solution for single edge cracked geometry with clamped ends. Their work was supported by experiments using aluminum 6061-T651 ${ }^{[12,13]}$. In the present work fatigue crack propagation for AISI 50100 steel is investigated. The crack length is determined using CMOD during the experiment. A complete procedure for calibrating the CMOD to the crack length is presented. In addition to that, CMOD values are obtained by numerical simulation relative to the crack length and the actual loading conditions under linear elastic conditions. A comparison of numerically and experimentally determined CMODs is presented. SENT specimens having $H / W=2$, with and without weldments, were used in the FCGR experiments conducted on MTS 810. Present work is a part of series research on the fatigue behavior of the welded precipitation hardened steel and a few initial experimental results are presented here.

\section{Experimental}

FCGR investigation was conducted on AISI 50100 steel. Chemical composition (wt.\%) of this material is given as follows: $\mathrm{C} 0.922$, Si $0.232, \mathrm{Mn} 0.454, \mathrm{P}$ 0.0136 , S 0.003 , Cr 0.400 and Fe balance. This is one of the commonly used precipitation hardening steel grades with a $0.4 \% \mathrm{Cr}$ and $0.9 \% \mathrm{C}$. Chromium is an alpha phase promoting alloy addition and its precipitates provide better edge retention in cutting tools.

Test specimens were cut from $2 \mathrm{~mm}$ thick plate having height $H=120 \mathrm{~mm}$ and width $W=30 \mathrm{~mm}$ on a DK7740 wire EDM machine. Tensile and high cycle fatigue tension tests were conducted on MTS 810 machine with a maximum load value of $9 \mathrm{kN}$, stress ratio $R=0.1$ and frequency is $10 \mathrm{~Hz}$. This load corresponds to a maximum stress of $150 \mathrm{MPa}$, which is less than $20 \%$ of the yield stress thus ensuring linear elastic fracture mechanics conditions. During experiments, the specimens were held in the MTS using wedge grips. Crack mouth opening displacement (CMOD) was measured by using MTS clip on gauge (Model No. 634.31F-24). Set of three tests were run on both welded and un-welded specimens (Fig. 1).

Although the specimens machined have a free standing length of $120 \mathrm{~mm}$, however when installed in the machine grips, the free specimen length to be considered for calculation purposes is $H=60 \mathrm{~mm}$ (length outside the grips), hence giving $H / W=2$. As is evident from Fig. 1, this value of $H$ is the effective height excluding the dimensions left on either side to hold the specimen in wedge grips. The type of

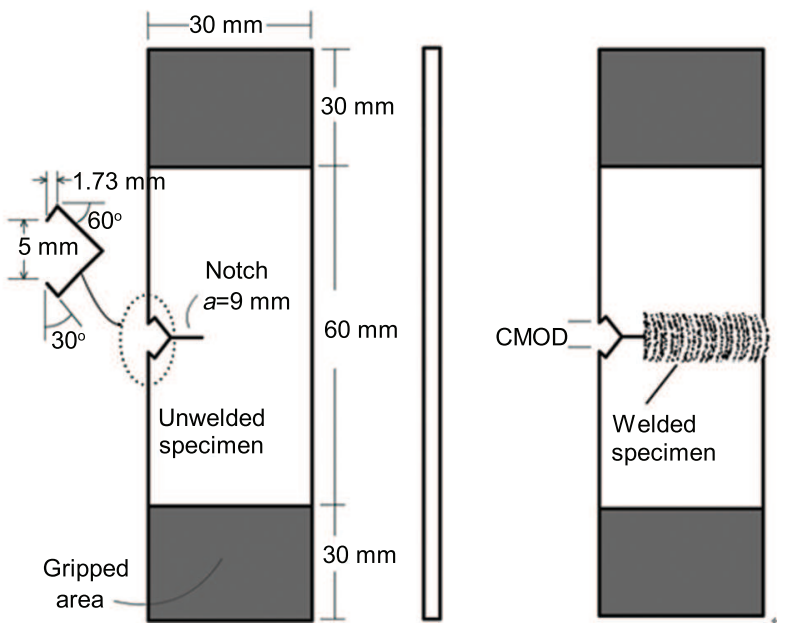

Fig. 1 Single edge cracked specimen with and without welding

specimen used in the experiments is single-edged notch tension (SENT). SENT was preferred over compact-tension, i.e., $\mathrm{C}(\mathrm{T})$ specimen, due to the fact that $\mathrm{C}(\mathrm{T})$ specimens of thin sheets is prone to buckling. However, there is one disadvantage in using the SENT specimens, that the range of $\Delta K$ is limited which makes interpretation of the results difficult. The crack length is basically interpreted from the clipon COD gauge measurement. To study FCGR behavior in the welded specimen, TIG welding was done on the specimen in such a way that the fatigue crack traveled through it, parallel to the weldment. Three groups of tests were carried out which are described below.

\subsection{Tensile test}

The tensile strength and hardness of material were found out experimentally. Although the exact simulation of the weld metal solidification is difficult to achieve through simple heat treatment, we have decided to conduct tensile tests for as-received material as well as for the normalized material because the macro hardness values of the weldment and the normalized material (at $870{ }^{\circ} \mathrm{C}$ ) match closely (33 HRC).

\subsection{Determination of CMOD vs. crack length (a)}

Indirect crack length measurement was obtained using a COD gauge placed at the mouth of the crack. Knife edges are machined integral to the specimen to mount the COD gauge. The procedure followed for this purpose is described below.

(1) A 'crack' with width of $0.2 \mathrm{~mm}$ is initially machined in the specimen using wire EDM up to $9 \mathrm{~mm}$. Although the crack has atomic dimensions at the crack tip radius, we have considered the machined thin notch as a crack as long as the specimen is loaded inside the elastic limit of the material. Practically it was observed that the applied maximum load does not exceed $20 \%$ of the elastic limit of the specimen. Thus 
the whole system may be considered to remain elastic during deformation for a short crack lengths. However, for a longer crack length this may not always be the case. The similarity in CMOD measurements of long notch and fatigue crack were later verified by measuring the crack directly with a microscope at different points of propagation. (2) The specimen with the machined crack is then loaded to $9 \mathrm{kN}$ in a increment of $1 \mathrm{kN}$ while noting CMOD at each increment. These readings are noted for loading and unloading of the specimen and the average is recorded. (3) Next crack length is increased by machining in the same specimen (using wirecut EDM) up to $18 \mathrm{~mm}$ in increments of $1 \mathrm{~mm}$ and the COD values are noted for each crack length following the procedure in the previous paragraph. This gives the values of CMOD vs. load (at constant crack length) and CMOD vs. crack ratio (at constant load).

\subsection{Numercial simulation of CMOD}

The CMOD vs. load for different crack lengths is obtained using ABAQUS/Standard ${ }^{\mathrm{TM}}$. The procedure used is described in detail in Ref. [14]. Here, only the relevant details are provided.

Detailed finite element analyses are performed on a 2D plane stress model 1-T SENT specimen, having a thickness $(t)$ of $2 \mathrm{~mm}$ using the software package ABAQUS/ Standard ${ }^{\mathrm{TM}}$. The analysis is carried out on the rectangular specimen with height to width ratio $(H / W)$ of 2 , as shown in Fig. 1.

Simulation is carried out for $0.3 \leq a / W \leq 0.6$ which corresponds to the crack length of $9 \mathrm{~mm}$ to $18 \mathrm{~mm}$ in a total width of $30 \mathrm{~mm}$. A conventional crack analysis mesh configuration is used with a focused ring of 3-node linear plane stress triangle (CPS3) elements around the crack tip as shown in Fig. 2. Around this first circle of triangular elements 6 concentric rings of 4-node bilinear plane stress quadrilateral, reduced integration, hour glass control CPS4R elements are generated. These rings are subsequently used for calculation of the J-Integral wherein the values on the first ring are ignored. There has to be convergence on

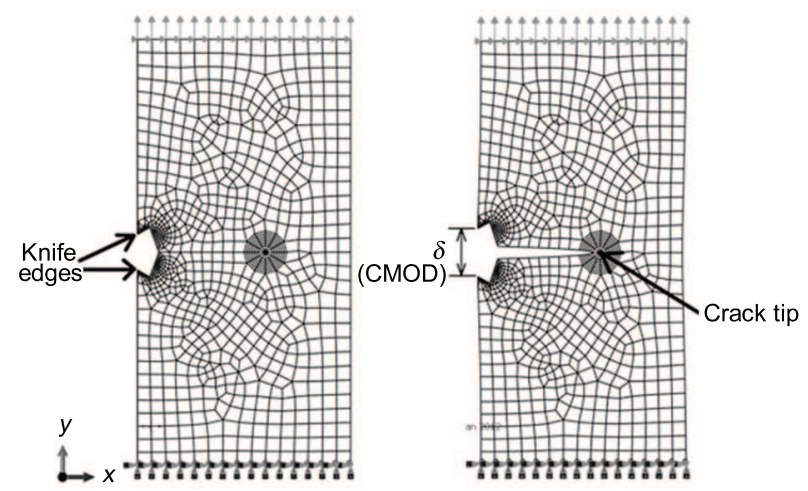

Fig. 2 CMOD calculation using numerical simulation on SENT specimens: (a) un-deformed; (b) deformed all other element rings for the results to be valid (see ABAQUS/Standard ${ }^{\mathrm{TM}}$ user's manual for a detailed explanation).

The position of the center of these rings defines the crack front. A typical 2D finite element mesh contains about 950 elements and 1020 nodes. A transverse plane surface is then chosen from the center of the rings to the crack edge which is defined as the partition or the crack line. During the finite element analysis ABAQUS/Standard ${ }^{\mathrm{TM}}$ duplicates the nodes on the crack plane and then assigns one set of nodes to one face and the other set to the other face. This creates a crack with no opening at the beginning, while a strain singularity at the crack tip. However since the large strain zone is very localized at the singularity the problem can be solved satisfactorily using small-strain analysis. The crack tip strain singularity depends on the choice of the material model used. In this analysis a linear elastic model is used.

CMOD values are measured on the knife edges. During experimentation also the CMOD gauge is installed on these knife edges as shown in the Fig. 2.

The values obtained experimentally and numerically are compared in the Fig. 3 which represents comparisons for different loading values at the same crack length. It can be observed that for small loading values the errors in comparison are lower (approximately $15 \%$ for $1 \mathrm{kN}$ for all crack lengths) whereas for higher loading values they are higher (approximately 20\% for 9 and $13 \mathrm{~mm}$ and up to $40 \%$ for the $18 \mathrm{~mm}$ ). The increase in error is probably due to the plasticity induced at the crack tip that can be felt by the COD gauge, whereas the simulation was linear elastic so does not take into account the effects of plasticity. This reasoning is also supported by the fact that at higher loading conditions and longer crack lengths the plasticity tends to increase causing a greater error in the measured and simulated CMOD. The trend for the simulated and measured CMOD is similar. However, since we are using the experimental values of CMOD for the SIF and crack length calculation this error will not be introduced into the FCGR curve calculations.

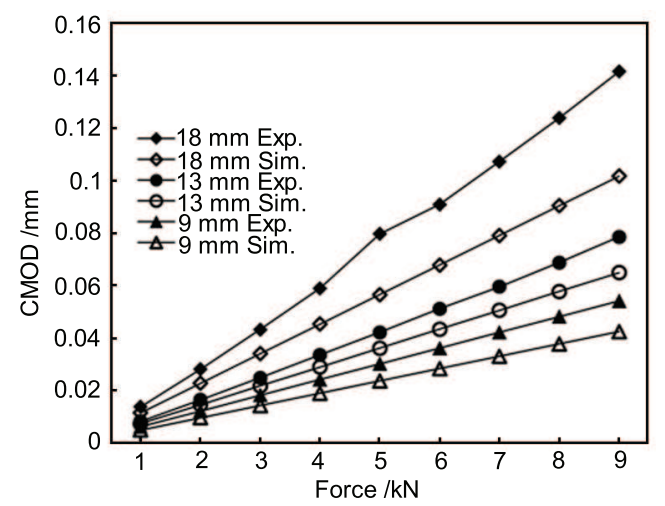

Fig. 3 Comparison of CMOD values obtained experimental and simulation 
2.4 Determination of fatigue crack growth rate curves (paris curves)

Paris curves were determined for the welded and un-welded specimens. Fatigue crack propagation experiments were carried out at $10 \mathrm{~Hz}$ with maximum load of $9 \mathrm{kN}$ for un-welded specimen and of $5 \mathrm{kN}$ for the welded specimen. The difference of maximum loads was to try to increase the range of $\Delta K$ during the experiments which becomes very limited at the high loads and long crack lengths.

The welding in the specimens is in the direction of crack propagation. Values of CMOD are recorded for each cycle. The crack length is thus interpreted with the help of the CMOD and the expression is determined in the results section.

\section{Results}

Likewise in the experimentation section, the results are expressed here in a sequential manner for each experiment performed.

\subsection{Mechanical properties}

The mechanical properties of the material are given in Table 1 . The values of the tensile tests are important to be determined if the material being tested can be treated using the linear elastic fracture mechanics assumptions. In our case, the applied maximum stress is $150 \mathrm{MPa}$. Thus it can be safely said that the specimen remains inside the elastic deformation range and the crack propagation can be characterized using LEFM assumptions.

\subsection{CMOD vs. crack length}

As stated above, the crack length has been determined using an indirect method of CMOD measurements. Fig. 4 and Fig. 5 present CMOD vs. load for constant crack length and CMOD vs. crack ratio at constant load.

It is noted that the CMOD vs. load is linear in the range of the loads that we have applied. This shows that the specimen exhibits linear deformation. At the same time CMOD vs. crack length exhibits a non linear behavior, which is typical of the increase in the correction factor used in the expression of SIF. Finally, an expression is determined to show the relationship between CMOD and crack length, independent of the loading conditions (Eq. (1)). This

Table 1 Mechanical properties of AISI50100 steel

\begin{tabular}{ccccc}
\hline $\begin{array}{c}\text { Specimen } \\
\text { type }\end{array}$ & $\begin{array}{c}\text { Hardness } \\
\text { /HRC }\end{array}$ & $\begin{array}{c}\text { Elastic } \\
\text { modulus } \\
\text { /MPa }\end{array}$ & $\begin{array}{c}\text { Yield } \\
\text { strength }\end{array}$ & $\begin{array}{c}\text { UTS } \\
/ \mathrm{MPa}\end{array}$ \\
\hline As-received & 37 & 194 & 790 & 1216 \\
Normalized & 33 & 207 & 710 & 1159 \\
\hline
\end{tabular}

is necessary to determine crack lengths for different loading conditions from the same expression.

$$
\begin{gathered}
\delta=0.0005 a^{2}-0.0031 a+0.0342 \quad\left(R^{2}=0.97\right) \\
\delta=\left\{f(a)^{*} F\right\} / 9
\end{gathered}
$$

where, $\delta=\mathrm{CMOD} ; f(a)$ is the function of crack length; $a$ is the crack length.

However, for our requirement we need crack length as a function of the CMOD. For this purpose the function was calculated directly for the stress variations $\Delta \sigma$ from the Fig. 4. The expression is given in Eq. (2) for un-welded specimen and in Eq. (3) for welded specimen.

$$
\begin{aligned}
& a=W \times\left(162.84 \delta^{3}-66.281 \delta^{2}+10.869 \delta-0.0526\right) \\
& a=W \times\left(963.53 \delta^{3}-211.58 \delta^{2}+19.025 \delta-0.0438\right)
\end{aligned}
$$

where $W$ is the width of the specimen.

The two expressions (2) and (3) have been determined independently to account for any effects of crack tip plasticity for a longer crack length.

\subsection{Comparison of numerically calculated and experimentally measured CMOD}

The numerically calculated CMOD gives lower values as compared to the experimentally measured values (Fig. 3). Variation in the results obtained by these methods increases with increase in load. This increase is more evident in the case of a longer crack.

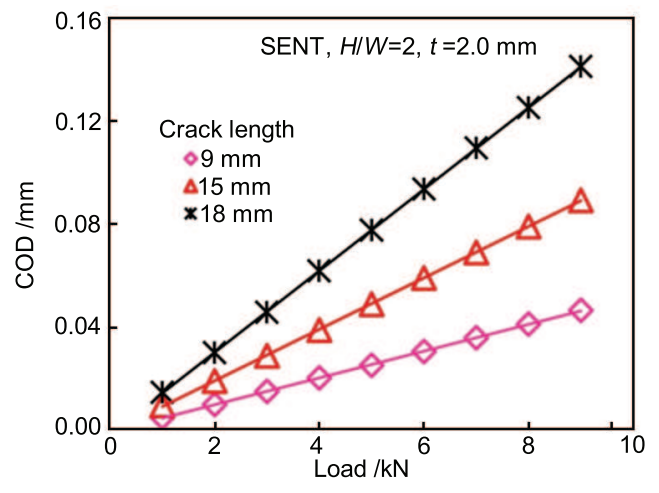

Fig. 4 CMOD vs. load

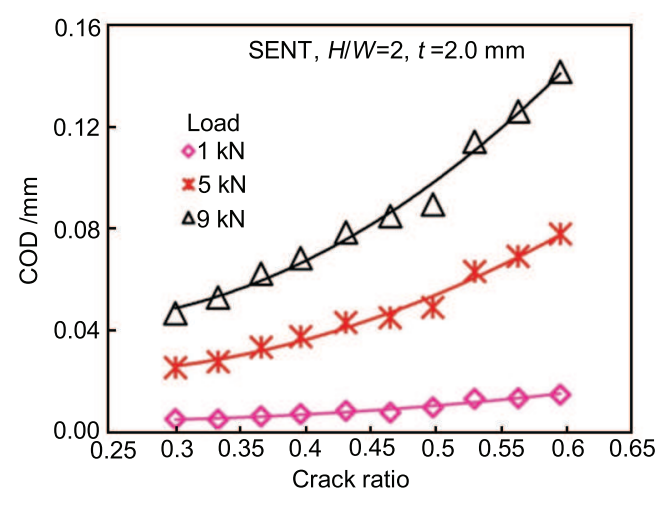

Fig. 5 CMOD vs. crack ratio 
This increase in variation between the two methods is probably due to the plasticity induced at the crack tip which is sensed by COD gauge, whereas the simulation does not take this into account the plasticity at the crack tip. However, since the experimental values of CMOD are used for the SIF and crack length calculation this error will not affect calculation of the fatigue crack growth rate.

\subsection{Determination of Paris curves for welded and unwelded specimen}

Knowing the specimen width, crack ratios $(a / W)$ were calculated for corresponding crack lengths and were plotted against CMOD (Fig. 6). Different curves for different load values (i.e., from 1 to $9 \mathrm{kN}$ ) applied during the tests are shown in this figure. The fatigue crack growth rate can thus be calculated from the Paris Law (4).

$$
\mathrm{d} a / \mathrm{d} N=C \Delta K^{m}
$$

where, $\Delta K$ is stress intensity factor.

$$
\Delta K=\Delta \sigma \cdot \sqrt{ }(\pi a) \cdot f(a / W)
$$

where, $f(a / W)$ is geometric correction factor. For SENT with $H / W=2$

$$
\begin{gathered}
f(a / W)=33.59(a / W)^{4}-67.63(a / W)^{3}+ \\
51.81(a / W)^{2}-16,85(a / W)+3.13
\end{gathered}
$$

The Paris curves for the welded and un-welded specimens are present in the Fig. 6.

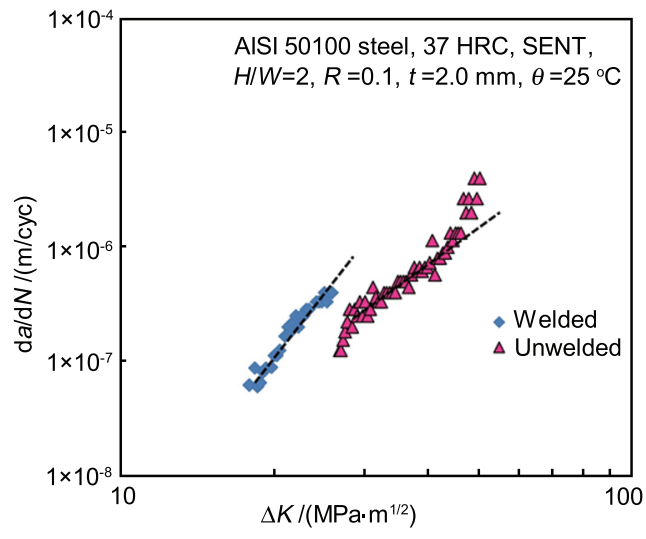

Fig. $6 \mathrm{~d} a / \mathrm{d} N$ vs. $\Delta K$ for welded and un-welded specimen ( $\theta$ is the temperature)

\section{Conclusions}

In this paper, the fatigue crack propagation of the welded and un-welded precipitation hardened tool steels is studied and compared. A method of indirect measurement of crack length is developed and described as well as the mathematical formulation necessary to calculate the stress intensity factors from the CMOD. An attempt has been made to correlate the experimentally and numerically obtained CMOD values. It is suggested that an elastic-plastic model be used to obtain more accurate CMOD values by simulation, which could be very helpful in determining the SIF directly from the CMOD without resorting to conversions into the crack length. Paris curves are established for the welded and un-welded material, using the experimentally measured CMOD values.

The CMOD vs. "a" expressions were developed using a "crack" machined with wire EDM. Although this cannot be considered a true crack, the long notch gives the same values of CMOD as long as it is in the elastic regime of loading. It was later verified also with a fatigue crack measured directly on an optical microscope.

Paris curves for the welded and un-welded specimens are compared. It is observed that for any value of $\Delta K$, the speed of propagation in the welded specimen is much greater than that of the un-welded specimen. There can be many reasons for this increase. The welded structure is dendritic which may exhibit higher propensity to crack as compared to the base metal which is rolled and heat treated in a manner that increases its resistance to fracture.

\section{Acknowledgements}

This work was supported by University of Engineering and Technology, Taxila.

\section{REFERENCES}

[1] T. Lassen and N. Récho, Fatigue Life Analysis of Welded Structures, Wiley-ISTE, London, 2006.

[2] K. Horikawa, A. Sakakibara and T. Mori, Trans. Jpn. Weld. Res. Inst. 18 (2) (1989)125.

[3] A. Wöhler, Z. Bauw 10 (1860) 583.

[4] R.E. Little, Tables for Estimating Median Fatigue Limits, ASTM STP731, ASTM, PA, 1981.

[5] A. Ohta, N. Suzuki and Y, Maeda, Int. J. Fatigue 19 (1997) 303.

[6] Y.H. Zhang and S. J. Maddox, Int. J. Fatigue 31 (2009) 1124.

[7] T. Nykanen, G. Marquis and T. Bjork, Int. J. Fatigue 31 (2009) 79.

[8] L.W. Tasy, C.S. Chung and C. Chen, Int. J. Fatigue 19 (1997) 25.

[9] M. Shah, C. Mabru and R. Rezai-Aria, Proc. Eng. 2 (2010) 2045.

[10] M.S.G. Chiodo and C. Ruggieri, Eng. Fract. Mech. 77 (2010) 415.

[11] R. John and B. Rigling, Eng. Fract. Mech. 60 (1998) 146.

[12] N. Marchand, D.M. Parks and R.M. Pelloux, Int. J. Fract. 31 (1986) 53.

[13] J. Ahmad, V. Papasptropoulos and A. T. Hooper, Eng. Fract. Mech. 38 (1991) 283.

[14] S.M.R. Shah, PhD Thesis: Investigation of crack propagation in $\mathrm{X} 38 \mathrm{CrMoV} 5$ tool steel at room temperature and $600^{\circ} \mathrm{C}$ on small scale specimens, Institut Clément Ader (ICA-Albi), Albi, France, 2010. (in France) 